Síntese - Rev. de Filosofia

v. 38 N. 120 (2011): 5-26

\title{
GROTIUS, DESCARTES E O PROBLEMA DO \\ CETICISMO NO SECULO XVII: \\ AS ORIGENS FILOSÓfICAS DO DEBATE JUSNATURALISMO \\ VS. POSITIVISMO LEGAL
}

(Grotius, Descartes and the issue of scepticism in the 17th century: the philosophical origins of the debate between natural law theory and legal positivism)

Marcelo Araújo *

Resumo: O objetivo deste texto é contribuir para uma compreensão da história do debate entre jusnaturalismo e positivismo legal. Esse debate teve sua origem no século XVII, mais especificamente no contexto do ceticismo moderno acerca dos fundamentos da legitimidade do exercício da autoridade política. As respostas de Hugo Grotius e René Descartes ao problema do ceticismo, como se pretende mostrar, contribuíram para a emergência do debate entre jusnaturalismo e positivismo legal.

Palavras-chave: Jusnaturalismo, positivismo legal, ceticismo, Hugo Grotius, René Descartes.

Abstract: This paper aims to develop a historical understanding of the debate between natural law theory and legal positivism. This debate has its roots in the 17th century, particularly in the context of the modern skepticism about the

\footnotetext{
* Doutor em Filosofia pela Universidade de Konstanz (Alemanha). Professor de Filosofia do Departamento de Filosofia da UERJ; professor de Filosofia do Direito da Faculdade de Direito da UFRJ; pesquisador do CNPq. Pesquisa apoiada financeiramente pela Fundação Humboldt e pelo CNPq. Artigo submetido a avaliação no dia 01/08/2010 e aprovado para publicação no dia 09/09/2010.
} 
justification for the exercise of political authority. I intend to show that the answer given by both Hugo Grotius and René Descartes against the skeptical attack contributed to the emergence of the debate between natural law theory and legal positivism.

Keywords: Natural law, legal positivism, skepticism, Hugo Grotius, René Descartes.

\section{Introdução}

$\mathrm{O}$ debate entre jusnaturalismo e positivismo legal foi, durante bas tante tempo, um dos tópicos mais discutidos no âmbito da filoso fia do direito. Mais recentemente, a agenda de discussão tem sido menos dominada pelos argumentos quer a favor quer contra cada uma das duas posições. No entanto, o debate entre "jusnaturalistas" e "juspositivistas" não foi de modo geral acompanhado de uma discussão sistemática sobre as origens filosóficas e históricas que permitiram a emergência do próprio debate. A pergunta filosófica sobre o que é uma lei, e sobre o que constitui a natureza do direito, é bastante antiga. Mas por que apenas no contexto dos séculos XVIII e XIX surge o projeto de se "separar" conceitualmente os âmbitos do direito e da moralidade? Como pretendo mostrar neste artigo, o debate entre jusnaturalismo e positivismo legal resulta da tentativa de se apresentar, no contexto do século XVII, uma resposta à pergunta sobre os fundamentos da legitimidade do exercício da autoridade política. Essa pergunta se tornou premente no contexto do século XVII em função do ceticismo moral e epistemológico, bastante influente na cultura dessa época. Como pretendo mostrar, as reações de Grotius e Descartes à pergunta quanto aos fundamentos da legitimidade do exercício da autoridade política constituem as origens do denominado debate entre "jusnaturalistas" e "juspositivistas."

\section{Legitimidade da autoridade política e ceticismo}

A maior parte do tempo, ainda que sem nos darmos conta disso, estamos submetidos a uma diversidade de leis e normas que não apenas regulam nossa conduta, mas também determinam parte de nossa identidade: votamos para presidente, paramos no sinal de trânsito, pagamos impostos, ou somos reconhecidos oficialmente como advogados, estudantes, médicos, ou brasileiros por força de uma diversidade de leis, normas, decretos e outros procedimentos jurídicos. Mas o que, afinal, confere legitimamente a uma pessoa, a um grupo de pessoas, ou, em última instância, a uma entidade abstrata como o Estado a autoridade para nos impor tais leis e normas? Ao longo da tradição do pensamento filosófico, diferentes respostas

$6 \quad$ Síntese, Belo Horizonte, v. 38, n. 120, 2011 
foram dadas à pergunta quanto à legitimidade do exercício da autoridade política.

Uma das respostas mais antigas à pergunta sobre legitimidade da autoridade política provém da ideia teológica segundo a qual Deus nos dá lei. Ao criar o mundo, Deus teria também criado leis para regrar a conduta dos homens no contexto da vida em sociedade. Segundo essa concepção, as leis criadas por Deus seriam passíveis de conhecimento, pois elas teriam sido "reveladas" por Deus aos homens. Alternativamente, essas leis seriam passíveis de conhecimento porque poderiam ser "descobertas" pela razão humana. Mas qualquer que seja nosso acesso epistêmico às leis de Deus, a consequência desse "conhecimento" para a filosofia do direito era clara: a vida em sociedade deveria ser organizada de tal modo que as leis positivas não entrassem em conflito com as leis de Deus. ${ }^{1}$ Dessa forma, as leis divinas não apenas constituiriam a fonte de legitimação das instituições políticas em que vivemos, mas nos dariam também um senso de identidade como criaturas de Deus, a quem deveríamos obediência e respeito. Embora algumas sociedades políticas sejam, ainda hoje, sociedades teocráticas, é desnecessário mencionar que essa resposta à pergunta quanto à legitimidade da autoridade política é bastante insatisfatória. Ela envolve problemas metafísicos relativos à existência de Deus e à existência de comandos divinos; e problemas epistemológicos relativos à nossa capacidade de conhecer as obrigações que Deus supostamente nos teria imposto. A partir da época moderna, alguns filósofos começaram a articular teorias acerca da legitimidade da autoridade política, sem, porém, se comprometerem com teses teológicas. No cerne das teorias modernas sobre a legitimidade da autoridade política estão os conceitos de "lei natural" e de "direito natural", por oposição ao conceito de "lei divina."

A ideia segunda a qual haveria certas "leis naturais", para além das "leis positivas", é bastante antiga. Essa ideia já se encontra, por exemplo, nas obras de Aristóteles, Cícero, Santo Agostinho, Tomás de Aquino e outros autores na tradição do jusnaturalismo pré-moderno. ${ }^{2}$ No entanto, a concepção pré-moderna de "lei natural" pareceu a vários filósofos modernos não menos problemática do que a própria ideia de lei divina. Com efeito, como poderíamos realmente nos certificar da existência de "leis naturais", ou como poderíamos conhecer com precisão seu conteúdo? As leis naturais seriam passíveis de algum tipo de observação empírica? A partir da época moderna, as tentativas de se justificar a legitimidade do exercício da autoridade política, quer por apelo à ideia de "lei divina", quer por apelo à ideia de "lei natural", começaram a ser sistematicamente criticadas. Essas críticas, a meu ver, resultam em larga medida do ressurgimento do interesse pelo ceticismo nos séculos XVI e XVII.

\footnotetext{
${ }^{1}$ BURKHARDT (1980, p. 694-706); MELANCTHON (1962, p. 506-510).

${ }^{2}$ FINNIS (1980); D’ENTRÈVES (1951).
} 
Durante a Renascença, como se sabe, ocorreu uma espécie de redescoberta da cultura da Antiguidade greco-romana. Os textos de autores céticos como, por exemplo, Sextus Empiricus, praticamente desconhecidos durante a Idade Média, foram inicialmente retomados como mais uma fonte de informação sobre a cultura da Antiguidade. No entanto, aos poucos, o problema do ceticismo passou a ser discutido em praticamente todos âmbitos da cultura moderna, sobretudo no âmbito da teologia, da moral, e da epistemologia. Como afirma Richard Popkin, houve nessa época uma "crise pirrônica."3 Num contexto como esse, não é de se estranhar que algumas ideias jurídicas e morais tradicionais tenham entrado em crise. Com efeito, com base em argumentos céticos, passou-se a questionar a própria existência das supostas normas mais fundamentais, em função das quais a legitimidade das leis positivas deveria ser avaliada. Uma das normas mais fundamentais, na tradição do pensamento cristão, dizia respeito ao "mandamento" que exigia do indivíduo amar os outros indivíduos assim como ele ama a si próprio:

“Mestre, qual é o maior mandamento da Lei? Jesus respondeu: 'Amarás ao Senhor teu Deus de todo o teu coração, de toda a tua alma e de todo o teu entendimento. Esse é o primeiro mandamento [é $\nu \tau o \lambda \eta ́$ ]. O segundo é semelhante a esse: Amarás o teu próximo como a ti mesmo. Desses dois manda-

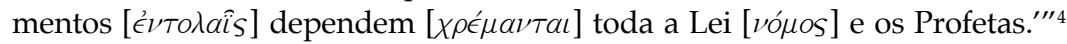

A validade da "lei" positiva ( $\nu o ́ \mu o s)$, segundo essa passagem bíblica, estaria

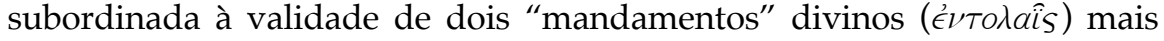
fundamentais. A relação de subordinação entre um e outro tipo de norma

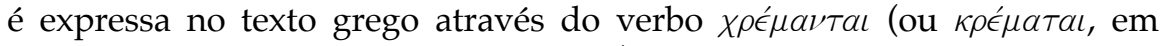
algumas edições do Novo Testamento), que sugere a metáfora de uma norma como que "pendurada" ou "suspensa" pela outra. Essa relação de subordinação da lei positiva a certas leis mais fundamentais é retomada mais tarde por Tomás de Aquino. Na Suma Teológica, Tomás de Aquino sustenta que o conceito de "lei" (lex) envolve o conceito de "bem comum" (bonum commune), e que, portanto, qualquer preceito humano que entre em conflito com a "ordenação" do bem comum não teria "razão de lei" (rationem legis).

"Portanto, é necessário que, dado que a lei [lex] se nomeia maximamente segundo a ordenação do bem comum, qualquer outro preceito sobre uma obra particular não tenha razão de lei a não ser segundo a ordenação ao bem comum. E assim toda lei se ordena ao bem comum [omnis lex ad bonum commune ordinatur]." ${ }^{5}$

\footnotetext{
${ }^{3}$ POPKIN (1979, p. 1-17). Cf. SCHMITT (1972); SCHNEEWIND (1991, p. 294).

${ }^{4}$ Novo Testamento, Mateus (22: 37-40). Cf. ibid. João (13:34): "dou-vos um mandamento novo: que vos ameis uns aos outros."

${ }^{5}$ AQUINO, Suma Teológica, Ia IIae, Q. 90 art 2. Cf. Q. 90 art. 4: "E assim pode-se colher dos quatros elementos anteriormente ditos a definição de lei [lex] que não é outra coisa que uma ordenação da razão para o bem comum, promulgada por aquele que tem o cuidado da comunidade."
} 
Na Suma Teológica Tomás de Aquino defende também que todo o indivíduo teria uma "inclinação natural" (inclinatio naturalis) para a promoção do bem comum. Isso, evidentemente, não exclui a possibilidade de ocasionalmente agirmos em dissonância com essa "inclinação natural." Contudo, ações desse tipo representariam, segundo Tomás de Aquino, uma perversão da verdadeira natureza humana. ${ }^{6}$

No entanto, no contexto do debate cético moderno, pareciam cada vez menos convincentes tanto a justificação teológica quanto a justificação filosófica para a tese segundo a qual haveria "mandamentos" divinos ou "leis" naturais às quais as leis positivas deveriam estar vinculadas. Uma estratégia para lidar com o problema do ceticismo consistia, então, em empregar no âmbito de investigação de questões morais e jurídicas o mesmo tipo de metodologia científica que vinha sendo aplicado com sucesso em outros âmbitos de investigação da época, como a astronomia e a física. $\mathrm{O}$ método aqui em questão era o método matemático.

As proposições mais básicas da matemática, com efeito, eram consideradas autoevidentes, formando assim os axiomas a partir dos quais proposições mais complexas e teoremas poderiam ser estabelecidos. Esses teoremas, por sua vez, poderiam ser aplicados na descrição de fenômenos naturais como, por exemplo, a órbita dos planetas em torno do Sol, o percurso de uma bola largada do alto de uma torre, a trajetória de uma bala de canhão, a previsão de eclipses, etc. Contudo, haveria também no contexto de discussões morais e jurídicas, semelhantemente ao que ocorre no âmbito da investigação de fenômenos naturais, proposições autoevidentes ou axiomas de cuja validade nem mesmo o cético poderia duvidar? Para o cético moderno, não parecia nada evidente a existência de uma lei natural ou mandamento divino que obrigasse o indivíduo a agir tendo em vista o bem de outras pessoas da mesma forma que se visa o próprio bem. Por outro lado, mesmo o cético, como qualquer outro indivíduo, teria evidentemente um interesse na promoção de seu próprio bem, ainda que negasse a existência de qualquer obrigação moral para com outros indivíduos. $\mathrm{O}$ cético, com efeito, poderia negar que tem uma "inclinação natural" para não agredir ou matar outros indivíduos. Ele poderia alegar, por exemplo, que essa suposta "inclinação natural", que nos impele a não agredir ou matar arbitrariamente outros indivíduos, seriam apenas hábitos e disposições adquiridas no contexto da vida em sociedade. ${ }^{7}$ Contudo, o cético não poderia razoavelmente negar possuir uma inclinação natural para evitar sobre si as agressões ou ameaças de outros indivíduos. Dessa forma, o cético teria de admitir que existe pelo menos uma "lei" à qual todos os indivíduos esta-

\footnotetext{
${ }^{6}$ Ibid. Ia IIae, Q. 94.

${ }^{7}$ Cf. MONTAIGNE, Essais, I. cap. 22: "Les lois de la conscience que nous disons naître de nature, naissent de la coutume."
}

Síntese, Belo Horizonte, v. 38, n. 120, 2011 
riam "naturalmente" subordinados e que os impele a buscar, antes de qualquer coisa, a autopreservação, e apenas secundariamente a preservação de outros indivíduos. A estratégia metodológica para lidar com o problema do ceticismo moral, portanto, consistia em chamar a atenção do cético para uma propriedade inerente a qualquer indivíduo e cuja existência não poderia ser colocada em questão.

É interessante notar que essa é basicamente a mesma estratégia que será utilizada por Descartes para lidar com o problema do ceticismo epistemológico. Descartes, como se sabe, aceita em larga medida a validade do argumento cético, na Primeira Meditação. Mas ele procura também mostrar, na Segunda Meditação, que o cogito não pode ser objeto de dúvida. A consciência de si como res cogitans, segundo Descartes, seria o ponto de partida na refutação do ceticismo. Mas a "refutação" do ceticismo oferecida por Descartes é compatível com a dúvida acerca da existência de outros sujeitos. O ponto de partida para a refutação do cético moral, de modo análogo, consiste na percepção de si próprio como sujeito de um tipo de propriedade que é inerente à natureza humana, a saber: o interesse na promoção da autopreservação. $\mathrm{O}$ interesse pela promoção do bem de outros indivíduos, assim, passa a ser caracterizado como algo que ocasionalmente surge no indivíduo a partir de sua interação com outros indivíduos, e não mais como uma "inclinação natural." Dessa forma, o cético poderia continuar colocando em questão a legitimidade de mandamentos religiosos que nos obrigassem, por exemplo, a "amar o próximo." Ele poderia também continuar colocando em questão a existência de uma suposta lei natural que nos obrigasse a buscar "promover o bem comum." Contudo, o cético não poderia razoavelmente negar que ele próprio - como também qualquer outro indivíduo - busca em última instância a realização de seu próprio interesse. Se isso é assim, então uma resposta adequada à pergunta quanto à legitimidade do exercício da autoridade política não deveria partir de considerações acerca de "mandamentos" ou "leis" que dissessem respeito ao bem de outros indivíduos, ou da comunidade como um todo. A resposta deveria partir de considerações acerca de um tipo de normatividade que dissesse respeito, antes de qualquer coisa, ao bem do próprio indivíduo. Embora a posição defendida por Thomas Hobbes seja mais comumente associada às origens dessa perspectiva individualista na fundamentação do exercício da autoridade política, gostaria de me deter a seguir na argumentação de dois outros filósofos que escreveram suas principais obras antes da publicação do Leviathan. Refiro-me a Hugo Grotius e René Descartes.

Grotius e Descartes se deram conta das dificuldades que o problema do ceticismo representava para as teses jusnaturalistas tradicionais. Tanto Grotius quanto Descartes, além disso, assumiram que a dúvida cética deveria ser tratada através de um método matemático. Convém também mencionar que ambos pensadores escreveram suas respectivas obras no 
contexto da Guerra dos Trinta Anos (1618-1648), e que os dois estiveram em uma posição especial para observar, e mesmo tomar parte em alguns dos mais importantes conflitos políticos do século XVII. O envolvimento de Grotius com as questões políticas relacionadas às reivindicações dos protestantes na Holanda lhe custou uma sentença de prisão perpétua, em 1619. A maior parte de sua principal obra foi escrita em Paris, após sua fuga da prisão. Descartes, por sua vez, concluiu sua formação jurídica em 1616 e, mais tarde, serviu nas tropas de Maurício de Nassau, tendo observado de perto, por exemplo, o cerco de La Rochelle, conduzido pessoalmente por Richelieu, em 1628. ${ }^{8}$

A tese de Grotius, como pretendo mostrar na próxima seção, é que a busca pela satisfação dos interesses individuais mais básicos pode ser justificada moralmente, pois qualquer indivíduo, independentemente de especulações de ordem teológica, poderia ser considerado como sujeito de uma "qualidade moral." A essa "qualidade moral" Grotius dá o nome de "direito natural." Grotius inaugura uma vertente na tradição do pensamento jusnaturalista que busca investigar não tanto a ideia de "lei", mas a ideia de "direito" natural. É importante notarmos, por outro lado, que outros autores modernos procuraram, assim como Grotius, dar uma resposta ao problema do ceticismo. Mas eles, diferentemente de Grotius, não assumiram que os indivíduos seriam sujeitos de direitos naturais, compreendidos em termos de uma "qualidade moral" inata à pessoa. Descartes, por exemplo, pretende ter dado uma resposta ao ceticismo epistemológico, mas ele rejeita que possamos estabelecer racionalmente a existência de mandamentos divinos, ou de leis e direitos naturais. Por essa razão, surge com Descartes um problema: se não existem direitos naturais ou mandamentos divinos, e se não podemos conceber o indivíduo como sendo, por natureza, sujeito de "qualidades morais", como poderíamos então avaliar a legitimidade do exercício da autoridade política?

Há alguns autores na tradição do pensamento moderno que, como Descartes, endossam o ceticismo moral. Para essa tradição, não podemos estar realmente certos sobre a existência de direitos ou leis naturais, nem sobre a existência de mandamentos divinos. Por outro lado, para essa mesma tradição, a existência de "leis positivas" não poderia ser realmente colocada em questão. Dessa forma, se quisermos compreender o que é, de fato, uma lei, e qual é, em última instância, a natureza do direito, devemos dissociar a pergunta sobre o que é a lei da pergunta sobre como as leis devem ser. Para essa tradição, as leis, no sentido próprio do termo, são sempre leis positivas. Essa é, como se sabe, uma das teses fundamentais do "positivismo legal." Minha intenção é mostrar, na última seção deste artigo, a relevância do pensamento de Descartes para o surgimento do positivismo legal.

8 TUCK (1991, p. 501); GAUKROGER (1997, p. 64). 


\section{Grotius e o jusnaturalismo moderno}

As principais obras de Grotius são De jure praedae e De jure belli ac pacis (1625). O primeiro texto permaneceu desconhecido até 1864, sendo que apenas uma parte dele era conhecida ainda na época de Grotius, a saber: a parte publicada em 1609 com o título Mare liberum. Como se descobriu mais tarde, o texto Mare liberum corresponde, na verdade, ao capítulo 12 do livro De jure praedae. Tanto em De jure praedae quanto em De jure belli ac pacis Grotius procura examinar a questão acerca da legitimidade do exercício da autoridade política sem recorrer a teses teológicas. Na obra de 1625 Grotius chega a afirmar que nem mesmo Deus poderia mudar a lei natural: "O que discutimos até aqui teria um certo grau de validade, mesmo se concedêssemos aquilo que não pode ser concedido ... que Deus não existe. ${ }^{\prime 9} \mathrm{O}$ objetivo de Grotius, dessa forma, é tornar a investigação sobre a natureza do direito uma disciplina autônoma relativamente à teologia. Como ele afirma em uma outra passagem de De jure belli ac pacis: "O direito natural é tão imutável que nem mesmo Deus poderia alterá1o. ${ }^{\prime 10}$

Grotius, evidentemente, não é um representante do positivismo legal, pois, como veremos a seguir, ele não dissocia a investigação acerca da natureza do direito do exame de questões morais. Por outro lado, é possível já perceber na obra de Grotius uma característica que marcará mais tarde de modo bastante distintivo a tradição do positivismo legal, a saber: a tentativa de tornar o fenômeno jurídico objeto de uma investigação científica. No contexto da época em que Grotius viveu, esse projeto de cientifização do direito significava, sobretudo, dissociar a investigação jurídica de quaisquer especulações de ordem teológica, e proceder segundo um método matemático. ${ }^{11}$ Grotius se dá conta, porém, de que a investigação acerca da natureza do direito deve pressupor, evidentemente, que o próprio direito exista, e que o direito possa ser objeto do conhecimento humano. Mas essa

\footnotetext{
${ }^{9}$ De jure belli ac pacis: Prolegomena $\$ 11$ (GROTIUS, 2004, p. 40).

${ }^{10}$ De jure belli ac pacis: I, cap. $10 \S 5$ (GROTIUS, 2004, p. 81).

${ }^{11}$ De jure praedae: cap. 1 (GROTIUS, 2006, 17-18): "Assim como os matemáticos geralmente fazem qualquer demonstração concreta ser precedida da afirmação preliminar de certos axiomas gerais com relação aos quais todos estão facilmente de acordo, de modo que haja um ponto fixo a partir do qual se possa traçar a prova do que se segue, da mesma forma indicaremos certas regras e leis da natureza bastante gerais, apresentando-as como assunções preliminares que precisam ser relembradas mais do que aprendidas pela primeiras vez, com o propósito de estabelecer os fundamentos sobre os quais outras conclusões possam repousar seguramente.” Cf. De jure belli ac pacis: I, cap. 10 \$5 (GROTIUS, 2004, p. 81): "Embora o poder de Deus seja infinito, no entanto podemos dizer que existem coisas às quais esse poder infinito não se estende, porque elas não podem ser expressas por proposições que tenham algum sentido, mas encerram manifestamente uma contradição. Por exemplo, então, que Deus ele próprio não pode fazer com que duas vezes dois não sejam quatro, nem fazer com que o que é intrinsecamente mal não seja mal ...”
} 
era justamente a pressuposição que o ceticismo moral moderno colocava em questão. Por essa razão, logo no início de De jure belli ac pacis, Grotius caracteriza sua investigação como sendo, antes de qualquer coisa, uma refutação do ceticismo moral. O cético visado por Grotius é Carnéades, que se tornou conhecido na Antiguidade por ter argumentado tanto a favor quanto contra a ideia de justiça. ${ }^{12}$ Para o cético, as leis (jura) e a justiça (justitiæ) existem apenas em virtude dos interesses (utilitate) dos indivíduos. Leis ou direitos naturais, segundo a perspectiva cética, não existiriam realmente (jus autem naturale esse nullum). Como Grotius afirma:

“Como toda a discussão sobre o direito [jura] seria inútil, se o próprio direito não subsistisse, importaria, para recomendar nossa obra e preveni-la contra ataques, refutar em poucas palavras esse grave erro. Para não ter que lidar com uma multidão de adversários, demos a essa opinião errônea um advogado. Que filósofo se deveria preferir a Carnéades que tinha atingido esse grau de perfeição sonhado por sua escola, o de poder aplicar a força de sua eloquência a serviço da mentira de igual modo que à defesa da verdade? Esse filósofo, empenhado em combater a justiça, especialmente essa de que nos ocupamos agora, não encontrou argumento melhor para tanto do que este: os homens se impuseram, em vista de seu interesse, leis que variam de acordo com os costumes e que, entre os mesmos povos, muitas vezes mudam de acordo as circunstâncias. Quanto ao direito natural [jus naturale], esse não existe [esse nullum]; todos os seres, homens e outros animais se deixam arrastar pela natureza em função de suas próprias utilidades [utilitate]. Deduz-se, pois, que não há justiça ou, se houvesse uma, não passaria de suprema loucura, porquanto prejudica o interesse do indivíduo, preocupando-se em proporcionar vantagem a outrem."13

Carnéades deve representar nesse contexto o tipo de ceticismo defendido por autores modernos como, por exemplo, Montaigne e Charron. ${ }^{14}$ Se os argumentos a favor, e os argumentos contra a ideia de justiça são igualmente plausíveis, então não podemos estar realmente certos acerca da existência de princípios de justiça confiáveis e com base nos quais avaliaríamos a legitimidade da autoridade política, pois a validade de um argumento, segundo o cético, exclui a validade do outro argumento. No entanto, para refutar o ceticismo moral, Grotius não procura mostrar que apenas um dos argumentos - o argumento a favor da ideia de justiça - é válido, sendo o outro argumento inválido. $\mathrm{O}$ objetivo de Grotius, na verdade, consiste em mostrar que as teses que cada um dos argumentos visa estabelecer não são incompatíveis entre si. Essas teses são: (i) a de que os seres

\footnotetext{
12 WILKERSON (1988, p. 131-144).

${ }^{13}$ De jure belli ac pacis: Prolegomena §5 (GROTIUS, 2004, p. 36).

${ }_{14}$ TUCK (1983, p. 44): "To attack Carneades in 1604 or 1625 was not of course simply to attack a long-dead classical philosopher. It was primarily to attack the modern sceptics whose appeal to contemporary intellectuals was profound-and with whom the youthful Grotius himself seems to have had some sympathy."
} 
humanos buscam naturalmente a vida em sociedade; e (ii) a de que a natureza humana é essencialmente autointeressada. A primeira tese é retomada por Grotius, por exemplo, nos Prolegomena da obra de 1625. Nos parágrafos 6 e 8 Grotius afirma:

“Entre essas [sc. ações], que são próprias ao homem, encontra-se o desejo de sociedade [appetitus societatis], isto é, de comunidade, não de uma qualquer, mas pacífica e organizada (...) Entendida assim de uma maneira geral, a afirmação de que a natureza impele todo animal somente para suas próprias utilidades, não procede." ${ }^{\prime 15}$

“Este cuidado pela vida social [societatis custodia], de que falamos de modo muito superficial, e que é de todo conforme ao entendimento humano, é o fundamento do direito propriamente dito..."16

Segundo a tese (i), portanto, o homem buscaria viver em sociedade mesmo que isso não lhe fosse imediatamente vantajoso. A tese (i), porém, não exige, segundo Grotius, uma aceitação sem restrições da antiga tese aristotélico-tomista segundo a qual o homem seria por natureza um "animal político", ou que o homem teria uma "inclinação natural" para a promoção do bem comum. ${ }^{17}$ A tese aristotélico-tomista foi de modo geral endossada no contexto da filosofia moral pré-moderna porque, ao se admitir que o homem seria um "animal político", ou que teria uma "inclinação natural" para a promoção do bem comum, admitiam-se também como legítimas aquelas leis positivas que regulavam a comunidade no contexto da qual o homem supostamente realizaria sua verdadeira natureza. Essas leis, na medida em que seriam condições de possibilidade para a realização da verdadeira natureza humana, não seriam meras convenções sociais. As leis naturais seriam anteriores à constituição de qualquer comunidade política e, por essa razão, poderiam ser consideradas leis naturais. O problema, no entanto, é que nem na Antiguidade nem na Idade Média se admitia que a verdadeira natureza humana poderia ser realizada no contexto de qualquer comunidade política. Tanto a teoria política de Aristóteles quanto a teoria de Tomás de Aquino podem ser compreendidas como tentativas de se estabelecer as circunstâncias políticas que deveriam vigorar para que os indivíduos pudessem realizar sua verdadeira natureza e, portanto, para que eles pudessem esperar viver uma vida que seria boa para eles mesmos. Mas isso era inteiramente compatível com a ideia segun-

\footnotetext{
${ }^{15}$ De jure belli ac pacis: Prolegomena §6 (GROTIUS, 2004, p. 37).

${ }^{16}$ De jure belli ac pacis: Prolegomena $\$ 8$ (GROTIUS, 2004, p. 39). Cf. De jure praedae, cap. 2 (GROTIUS, 2006, p. 26)

17 TUCK (1983, p. 53): "It is important also to stress that according to Grotius this natural sense of society with all other men does not entail any obligation to help them, or to foster

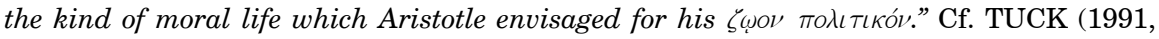
p. 507); SCHNEEWIND (1998, p. 71-72); GOUGH (1967, p. 80-1); SCHNEIDERS (1971, p. 70-2).
} 
do a qual a comunidade política poderia impor, para o bem do próprio indivíduo e da comunidade como um todo, uma concepção particular de boa vida, i.e. aquela concepção que fosse tomada como a única realmente compatível com a verdadeira natureza humana. ${ }^{18}$ Contudo, diante dos argumentos céticos, que foram retomados na época moderna, a tese segundo a qual haveria uma única concepção correta de boa vida, e um única forma aceitável de governo, passou a ser questionada.

Grotius, assim como o cético, rejeita a tese segundo a qual existiria uma única concepção correta de boa vida. Grotius rejeita também a tese segundo a qual haveria uma única forma aceitável de governo. ${ }^{19}$ Grotius sustenta que qualquer indivíduo é livre para escolher a concepção de boa vida que considerar melhor para si próprio. E pelas mesmas razões ele sustenta também que cada comunidade política poderia escolher para si própria a "forma de governo" (gubernationis forma) que melhor lhe conviesse. O que é relevante nessa escolha não é a excelência intrínseca dessa ou daquela concepção de boa vida, ou dessa ou daquela forma de governo, mas o fato de a escolha ter sido realizada em consonância com a vontade dos indivíduos. Como Grotius afirma no primeiro livro da obra de 1625:

Assim como há várias maneiras de viver [vivendi genera], umas melhores do que outras, e cada um é livre [liberum] para escolher, entre todas elas, a que preferir, de igual modo um povo pode fazer a escolha pela forma de governo [gubernationis formam] que quiser; e a extensão de seu direito não deve ser medida pela excelência de tal ou qual forma - questão que divide as opiniões [qua de re diversa diversorum sunt judicia] -, mas segundo sua vontade [ex voluntate]. ${ }^{20}$

Ao reconhecer que a vontade dos indivíduos deve ter precedência quando nos perguntamos quer pelo melhor tipo de vida, quer pela melhor forma de governo, Grotius termina por compartilhar com o cético uma tese fundamental. Assim como o cético, Grotius reconhece que é tamanha a diversidade de "opiniões" (judicia) na determinação da melhor forma de governo que não podemos apelar à outra instância normativa no exame dessas questões a não ser a vontade dos próprios indivíduos. E o que é naturalmente visado pela vontade dos indivíduos é a inclinação para a promoção do autointeresse. Dessa forma, Grotius se compromete também com a tese

\footnotetext{
${ }^{18}$ CONSTANT (1988, p. 310-311); MACPHERSON (1964, p. 263-278).

${ }^{19}$ HAAKONSSEN (1985, p. 249): "Already Aristotle had sought the foundation of law in people's social character. But in Aristotle it is a politically organized society that our nature prescribes for us, whereas in Grotius it is mere human sociability that is prescribed, with the question of the organization of the ensuing society being a further one." Cf. DARWALL (2006, p. 223-24).

${ }^{20}$ De jure belli ac pacis: I cap. 3 sec. 8 \$2 (GROTIUS, 2004, p. 177-78). Cf. De jure praedae: cap. 8 (GROTIUS, 2006, 136-37): "Assim como todo direito do magistrado vem a ele do Estado, da mesma forma o mesmo direito [jus] vem ao Estado a partir do indivíduo; e similarmente, o poder do Estado é o resultado de um acordo coletivo."
} 
(ii), a que me referi acima, a saber: a tese sobre o caráter autointeressado da natureza humana. Como ele afirma, por exemplo, em De jure praedae:

"Portanto, uma vez que Deus concebeu a criação e desejou sua existência, toda parte individual da criação recebeu dele certas propriedades naturais por meio das quais a existência pode ser preservada e cada parte pode ser guiada tendo em vista seu próprio bem, em conformidade, poder-se-ia dizer, com a lei fundamental inerente à sua origem. Desse fato os antigos poetas e filósofos deduziram corretamente que o amor, cuja primeira força e ação são direcionadas ao autointeresse, é o princípio de toda ordem natural. Consequentemente, Horácio não deveria ser censurado ao dizer, imitando os Acadêmicos, que o expediente poderia talvez ser denominado a mãe da justiça e da equidade, pois todas as coisas na natureza, como Cícero repetidamente insiste, são voltadas para si próprias, e buscam sua própria preservação e segurança." ${ }^{21}$

Como uma resposta ao problema do ceticismo, a tese (ii) poderia ser considerada bem pouco satisfatória, pois ela mais parece caracterizar Grotius como um cético do que como um autor interessado em refutar o ceticismo. Com efeito, Grotius reconhece na busca pela promoção do autointeresse a única característica natural na conduta humana. Por essa razão, ao longo do século XVII, muitos autores tiveram a impressão de que Grotius, no final das contas, não havia de fato dado uma resposta clara ao problema do ceticismo moral, e que sua própria posição não era muito diferente daquela defendida, por exemplo, por Hobbes no Leviathan. ${ }^{22}$

A posição defendida por Grotius, e que o diferencia do cético e de Hobbes, consiste em conferir um caráter moral à busca pela promoção dos interesses mais básicos que podem ser atribuídos a qualquer ser humano. Esses interesses básicos são, por exemplo, o interesse na preservação da própria vida, o interesse na manutenção da própria liberdade, ou o interesse na proteção de sua propriedade. ${ }^{23}$ Qualquer indivíduo estaria justificado a buscar para si próprio a satisfação de interesses desse tipo, não porque a natureza simplesmente o inclina a agir dessa forma, mas porque o indivíduo, segundo Grotius, pode se reconhecer como sujeito de uma "qualidade moral" que é constitutiva de sua própria natureza. A essa qualidade moral Grotius dá o nome de "direito natural" (jus naturale). Dessa forma, começa a surgir com Grotius uma vertente na tradição do pensamento jusnaturalista para qual o conceito de direito natural, por oposição ao conceito de lei natural, passa a ser o principal objeto de investigação. ${ }^{24}$ Até o início da

${ }^{21}$ De jure praedae, cap. 2 (GROTIUS, 2006, 21).

${ }^{22}$ TUCK (1999, p. 102) : “...it became to a degree a commonplace in late seventeenthcentury Germany that Grotius had failed to refute Carneades because his own basic idea was the same, and that there was at bottom little to choose between Grotius and Hobbes." Cf. TUCK (1983, p. 52); TUCK (1987, p. 115); TUCK (1991, p. 507); WESTERMAN (1998, p. $137 ; 168)$.

${ }^{23}$ Sobre o conceito de propriedade privada em Grotius, ver ARAUJO (2009). 
época moderna a palavra jus era tradicionalmente usada para designar diferentes conceitos: (i) o conceito de lei, (ii) o conceito de justiça, (iii) ou o conceito de direito, compreendido como a instituição do direito como um todo. Em sua obra de 1625, porém, Grotius introduz um novo sentido para a palavra jus, a saber: jus com uma "qualidade moral da pessoa."

Há um significado de direito [juris significatione] diferente do anterior, mas que dele decorre e que se refere à pessoa [ad personam refertur]. Tomado neste sentido o direito é uma qualidade moral da pessoa [Qualitas moralis personæ] para possuir ou fazer de modo justo [juste] alguma coisa. ${ }^{25}$

Dessa forma, a partir do século XVII, a palavra jus passou a ser usada para designar, sobretudo, o conceito de "direito subjetivo." O conceito de lei, por sua vez, passou a ser designado quase que exclusivamente pela palavra lex. A falta de uma distinção precisa entre os termos jus e lex levou Hobbes a afirmar, no início do capítulo 14 do Leviathan, que os filósofos antes dele não haviam feito essa distinção com clareza. ${ }^{26}$ - Evidentemente, a crítica de Hobbes não se aplica a Grotius.

O conceito de "direito natural", compreendido como uma "qualidade moral da pessoa", nos permite agora avaliar a legitimidade do exercício da autoridade política apelando-se para a ideia segundo a qual pessoas têm "direitos", e que esses direitos não podem ser legitimamente violados no exercício da autoridade política. Dessa forma, contra o cético, o que Grotius alega é que não podemos colocar em questão a existência dos direitos naturais, que são prerrogativas morais relativas à satisfação dos interesses mais básicos de qualquer indivíduo. ${ }^{27}$ Uma lei positiva que comprometa a satisfação dos interesses mais básicos dos indivíduos, portanto, pode ser reconhecida como injusta. Essa mudança no foco da investigação jurídica, que passa a incidir não tanto sobre a "lei natural" à qual estaríamos submetidos, mas sobre os "direitos naturais" de que todos seríamos sujeitos,

\footnotetext{
${ }^{24}$ D'ENTRÈVES (1951, p. 59): “The modern theory of natural law was not, properly speaking, a theory of law at all. It was a theory of rights. A momentous change has taken place under cover of the same verbal expressions. The ius naturale of the modern political philosopher is no longer the lex naturalis of the medieval moralist nor the ius naturale of the Roman lawyer. These different conceptions have in common only the name. The Latin word ius is the cause of the ambiguity." SKINNER (1994, p. 39-40): "Moral philosophers in ancient and medieval Europe were greatly concerned with the question of distributive justice, and thus with the question of what is due to us as a matter of right. But they lacked a vocabulary to articulate the suggestion that what is due to us as matter of right is something which can in turn be called our right. It was only during the later Middle Ages that this conception of 'subjective' right began to enter European political discourse. And it was only in the course of the seventeenth century that the concept began to acquire that moral hegemony which it has never subsequently lost." Cf. também HARRISSON (1999, p. 95); MAcINTYRE (1981, p. 68-69).

${ }^{25}$ De jure belli ac pacis: I cap. 4 (GROTIUS, 2004, 74).

${ }^{26}$ Leviathan, cap. 14

${ }^{27}$ HAAKONSSEN (1998, p. 132); TUCK (1972, p. 53; 74); MAUTNER (2005, p. 577-601).
} 
teve uma repercussão sem precedentes sobre o modo como problemas políticos fundamentais passaram a ser discutidos e compreendidos. Essa mudança no foco da investigação influenciou também a própria concepção de identidade pessoal que passou a predominar a partir da época moderna, pois os indivíduos passaram a se compreender a si próprios como sujeitos de direitos. Ao se perguntar sobre quais condições deveriam ser satisfeitas para que uma lei positiva pudesse ser considerada legítima, já não era mais necessário apelar à ideia de uma lei natural à qual a lei positiva deveria se conformar. Legítimas passaram a ser consideradas as leis positivas que asseguravam a não-violação dos "direitos naturais" dos indivíduos a elas submetidos. ${ }^{28}$

Evidentemente, a primeira pergunta que podemos nos fazer é se, e em que medida, o conceito de "direito natural" é, de fato, menos problemático do que o conceito de "lei natural." Diante do ataque cético, a alternativa mais razoável e condizente com a metodologia científica da época talvez não fosse substituir a doutrina da "lei natural" por uma doutrina do "direito natural", como propôs Grotius, mas abandonar inteiramente o projeto de buscar na natureza a "fonte" do direito. Essa foi, com efeito, a reação de Descartes ao ceticismo moral.

\section{Descartes e a crítica ao jusnaturalismo moderno}

Descartes não costuma ser visto como um filósofo relevante na tradição do pensamento jurídico. Contudo, é possível reconhecermos em Descartes uma espécie de precursor do positivismo legal. Embora Descartes pretenda ter oferecido uma refutação do ceticismo epistemológico, ele permaneceu cético quanto à possibilidade de fundamentarmos a legitimidade do exercício da autoridade política em bases metafísicas, pois não podemos ter ideias "claras e distintas" acerca de entidades normativas tais como leis e direitos naturais, ou comandos divinos. Somente podemos ter ideias claras e distintas a respeito de "naturezas simples", que são os conceitos mais básicos em torno dos quais se constitui nosso conhecimento do mundo. Descartes oferece como exemplo de "naturezas simples" as ideias de tempo, de extensão, de movimento, de número, de forma, de existência, etc. ${ }^{29}$ Contudo, não existem, segundo Descartes, "naturezas simples" relativas a conceitos

${ }^{28}$ SCHNEEWIND (1990, p. 89): "If Grotius was breaking new ground in taking on skepticism, he was also innovating by introducing a new understanding of rights. He treated rights as attributes that each individual possesses independently of membership in any group or society and prior to being under any law." (...) "Against the skeptic it would seem less effective to claim that all human possess rights than to hold that all are moved to some extent by self-interest. Yet both claims are important to Grotius's theory." ${ }^{29}$ ARAUJO (2002, p. 163-186). 
morais. Não temos uma faculdade de intuir o que é moralmente certo ou errado, da mesma forma que temos uma faculdade para "intuir", por exemplo, que um triângulo é composto por três lados. Isso significa que, para Descartes, a tradição jusnaturalista pré-moderna, que assume que teríamos um poder de conhecer leis naturais e mandamentos divinos, é passível de questionamento. No entanto, diferentemente de Grotius, Descartes não procura substituir a teoria pré-moderna sobre "leis" naturais por uma teoria sobre "direitos" naturais.

Descartes jamais apresentou de modo sistemático uma teoria moral, tendo deixado em aberto a questão sobre os fundamentos últimos da legitimidade do exercício da autoridade política. O ceticismo de Descartes no âmbito da moral, a meu ver, terminou por contribuir para o surgimento do positivismo legal. Com efeito, ao endossar a posição cética, negando que Deus ou a natureza pudessem ser concebidos em algum sentido relevante como fontes do direito, Descartes tinha então duas alternativas: (i) abandonar inteiramente o projeto de darmos uma resposta sistemática à pergunta sobre a natureza do direito, uma vez que essa questão foi tradicionalmente investigada no contexto de teorias morais vulneráveis aos ataque céticos; ou (ii) limitar a investigação sobre a natureza do direito ao estudo da lei positiva, pois a lei positiva é o único tipo de norma cuja existência não podemos razoavelmente colocar em questão. $\mathrm{O}$ positivismo legal consiste em um tipo de investigação que segue a segunda alternativa: como a questão acerca da natureza do direito foi tradicionalmente investigada no contexto da filosofia moral, e como a moral, ela própria, não é passível de uma fundamentação teológica ou metafísica, seria então necessário separar os âmbitos do direito e da moralidade de modo a eliminar da investigação jurídica quaisquer resquícios teológicos ou metafísicos.

Alguns autores tradicionalmente vistos como precursores do positivismo legal se comprometeram de modo bastante claro com a posição (ii). Jeremy Bentham, por exemplo, sustenta que a tentativa de encontrar na natureza a "fonte" (source) dos denominados direitos naturais seria um procedimento metodológico tão equivocado quanto buscar na vontade de Deus a fonte das leis morais: "Qual é a fonte destes direitos inalienáveis - estes direitos inabolíveis? (...) Feitos por quem? Não por Deus - pois eles não admitem nenhum, mas pela deusa deles: a Natureza." ${ }^{30}$ Bentham parece ter se dado conta de que o jusnaturalismo moderno apenas substituiu o conceito de "Deus" pelo conceito de "natureza", sem que essa manobra linguística resolvesse de modo satisfatório a questão filosófica sobre a "fonte" do direito. Posteriormente, outros autores na tradição do positivismo legal, tais como Hans Kelsen e H. L. A. Hart, também chamaram atenção para esse problema e negaram, da mesma forma que Bentham, o projeto de se buscar em Deus ou na natureza a fonte do direito. ${ }^{31}$ A despeito da diversidade de posições

${ }^{30}$ BENTHAM (1987, p. 54-55). 
defendidas por autores como Bentham, Kelsen, e Hart uma tese que esses autores procuram defender é que a "fonte" do direito deve ser buscada em contextos de governo. Mais especificamente, é apenas no âmbito do Estado que leis e direitos passam propriamente a existir. A questão que devemos nos colocar agora diz respeito à posição de Descartes relativamente às alternativas (i) e (ii). Descartes endossa claramente a posição (i), mas ele não se compromete com a posição (ii) de modo suficientemente claro para que possamos considerá-lo um autêntico representante do positivismo legal. Por outro lado, ao se pronunciar ocasionalmente sobre questões morais e políticas, Descartes defende uma tese que constituirá mais tarde um dos pressupostos básicos de diferentes versões do positivismo legal, a saber: a tese sobre a preeminência do Estado como única fonte do direito.

Descartes justifica sua relutância em tratar de questões morais e políticas alegando que compete ao soberano, e apenas ao soberano, prescrever normas para a conduta da vida em sociedade: “...eu creio que compete apenas aos Soberanos, ou àqueles por ele autorizados, se meter a regrar os costumes [mœurs] dos outros. ${ }^{\prime 32}$ Descartes, portanto, reconhece na figura do soberano a única fonte do direito. Não podemos perder de vista aqui que Descartes estava escrevendo no contexto da Guerra dos Trinta Anos, um período de intensos conflitos religiosos na Europa. Em um contexto como esse, se cada indivíduo procurasse implementar uma concepção particular de moral (mœurs), o resultado seria a anarquia e acirramento dos conflitos, pois a natureza da moralidade, segundo Descartes, é tal que não poderíamos realmente esperar que argumentos racionais pudessem se apresentados em defesa de uma concepção específica de moral em detrimento de outra concepção. Como Descarte afirma na sexta parte do Discurso do Método:

“Pois, no tocante aos costumes (mœurs), cada qual segue de tal maneira sua própria opinião que se poderiam encontrar tantos reformadores quantas são as cabeças, se fosse permitido a outros, além dos que Deus estabeleceu como soberanos dos povos (...) empreenderem aí alguma mudança" ${ }^{\prime 3}$

A referência a Deus nessa passagem poderia sugerir que Descartes, de alguma maneira, justificasse o exercício da autoridade política tendo em vista algum tipo de direito divino por parte do soberano. Não me parece, porém, que seja essa realmente a posição defendida por Descartes. Ao atribuir ao soberano a tarefa de regular a conduta dos indivíduos no âmbito da vida em sociedade, Descartes não assume que o soberano deva se comprometer com uma concepção determinada de moral. Pelo contrário, o soberano, ele próprio, deveria suspender o juízo a respeito de questões morais e religiosas de modo a garantir a ordem entre seus cidadãos. ${ }^{34} \mathrm{Em}$

${ }^{31}$ HART (1983 p. 201); KELSEN (2000, p. 49).

${ }^{32}$ AT V, 86-87 (citações de Descartes conforme a edição de Adam e Tannery, seguidas do número do volume, e do número da página).

${ }^{33}$ AT VI, 61. 
uma outra passagem do Discurso do Método, Descartes sustenta que uma comunidade política é "bem governada" (bien policés) na medida em que suas leis tenham como fonte a vontade de um único indivíduo, independentemente de seus méritos morais.

“Assim, imaginei que os povos que, tendo sido outrora semisselvagens e tendo-se civilizado apenas pouco a pouco, foram fazendo suas leis somente à medida que a incomodidade dos crimes e das querelas a isso os forçou não poderiam ser tão bem governados [policés] como aquele que, desde o momento em que se reuniram, observaram as constituições de algum prudente legislador [prudent Legislateur]. (...) e se Esparta foi outrora tão florescente, não foi por causa da bondade de cada uma de suas leis em particular, visto que muitas eram muito estranhas e até contrárias aos bons costumes [bonnes mœurs]; mas foi porque, tendo sido inventadas por um só indivíduo, todas tendiam ao mesmo fim." ${ }^{35}$

A expressão "governado" (policé), como nota Étienne Gilson, tem aqui um sentido propriamente jurídico. ${ }^{36}$ É possível observarmos nas passagens do Discurso do Método, em que Descartes se refere a questões de ordem jurídica, uma clara analogia entre o papel da razão na construção do conhecimento humano, de um lado, e o papel do soberano na administração do Estado, do outro lado. A tese de Descartes é que a única fonte do conhecimento é a razão. Se a construção do conhecimento for respaldada por outras fontes que não unicamente a razão, tais como, por exemplo, as percepções sensíveis, os preceitos da Escolástica, a opinião de outras pessoas, etc., o que teremos como resultado não é a ciência, mas uma pletora de opiniões divergentes. Da mesma forma, se buscarmos as leis em uma diversidade de fontes, tais como a "natureza", a "moral" (mœurs), ou preceitos religiosos, não teremos um Estado bem governado, mas anarquia. Descarte recorre a essa analogia, por exemplo, na sequência da segunda parte do Discurso do Método:

"E como a multiplicidade de leis fornece frequentemente desculpas aos vícios, de modo que um Estado é bem melhor regrado [reiglé] quando, tendo bem poucas leis, elas são rigorosamente observadas; assim, em vez desse

\footnotetext{
${ }^{34}$ LEVI (2000, p. 155): "The philosopher who came nearest to summing up Richelieu's ethical values, and whose expression of his moral ideal certainly derived from du Vair, was Descartes, born in 1596 who was Richelieu's nearly exact contemporary." (...) "Richelieu, in his subordination of all personal interests to those of the state, was the ultimate product of the culture of gloire, whose underlying ethic had been elaborated by du Vair and then Descartes." Cf. MOOTE (1991, p. 271-272): "To be sure, Descartes in this work [sc. Discourse on Method], as well as in his comprehensive Meditations of 1641, explicitly ruled out the questioning of political and social authority. But Cartesian philosophy eventually joined other elements of the scientific revolution in creating the eighteenth-century Enlightment. The Enlightment, in turn, assaulted the divine-right monarchy and society of orders that Descartes had respected, and that had vied for primacy in Louis XIII's world." Cf. também TUCK (1983, p. 47); ACZEL (2005, p. 125-130).

${ }^{35}$ AT VI, 12.

${ }^{36}$ GILSON (1962, p. 164). Gilson toma como base o Dictionnaire de l'Académie, de 1694, que define police nos seguintes termos: "'ordre, le règlement qu'on observe dans um État, dans une république, dans une ville."
} 
grande número de preceitos de que a Lógica é composta, acreditei que me bastariam os quatro seguintes, contanto que tomasse a firme e constante resolução de não deixar uma única vez de observá-los." 37

A unidade da razão no âmbito da epistemologia tem como correlato, no âmbito da jurisprudência, a unidade do soberano como única fonte do direito. E o que confere ao soberano o "direito" de governar não é nem prerrogativa divina nem excelência moral, mas a capacidade de manter a ordem entre os indivíduos a ele subordinados. Nos poucos textos em que Descartes emprega a palavra "direito" (droit) o que ele tem em mente, diferentemente de Grotius, não é uma "qualidade moral da pessoa", mas uma prerrogativa do soberano no sentido de fazer o que for necessário para garantir sua própria preservação. Se Descartes ocasionalmente se refere a uma suposta autorização divina para que o soberano exerça sua autoridade, essa autorização é compreendida apenas em termos de "poder", e não como um tipo de excelência moral. Em uma carta a Elisabeth, Descartes nega que a relação entre soberanos deva estar subordinada a algum princípio de justiça, pois o "direito" do soberano não está subordinado a concepções de justiça, mas ao poder de garantir sua própria sobrevivência enquanto soberano:

“... a justiça entre os soberanos não tem os mesmos limites da justiça entre indivíduos. Parece-me que nesse caso Deus dá o direito [droit] àqueles a quem ele dá poder." ${ }^{\prime 38}$

Um soberano não tem relativamente a outro soberano nenhum tipo de obrigação moral que não possa ser redescrita em termos de vantagem individual. Mesmo a obrigação de cumprir promessas ou tratados deve ser considerada tendo em vista o cálculo das vantagens e desvantagens resultantes do respeito ou não aos contratos firmados com outros soberanos. Para Descartes, com efeito, o próprio "direito internacional" (droit des gens) dispensa o soberano de cumprir tratados ou promessas naquelas ocasiões em que está em jogo sua sobrevivência ou ruína. ${ }^{39}$ Diferentemente de Grotius, portanto, Descartes rejeita a possibilidade de estabelecermos princípios de justiça no âmbito das relações internacionais, pois a fonte do direito, em última instância, não é

\footnotetext{
37 AT VI, 18.

${ }^{38}$ AT IV, 487. Cf. ibid. 487-88: "Devemos distinguir também entre os súditos, os amigos ou aliados, e os inimigos. Pois, com relação a esses últimos, temos praticamente permissão de tudo fazer, contanto que tiremos alguma vantagem para nós próprios ou para os súditos; e não desaprovo, nessa ocasião, que associemos a raposa ao leão, e juntemos o artificio à força. E incluo mesmo entre os inimigos todos aqueles que não são nem amigos ou aliados, na medida em que temos direito [droit] de lhes fazer guerra quando é para vantagem própria, e que, começando a se tornar suspeitos e poderosos, temos a ocasião de desafiá-los."

${ }^{39}$ AT vi 488: "No que concerne aos aliados, um príncipe deve cumprir rigorosamente sua palavra, mesmo quando isso lhe for prejudicial; pois isso não lhe poderia ser tanto assim, na medida em que a reputação [réputation] de não deixar de modo algum de fazer aquilo que promete lhe é útil; e ele somente pode adquirir essa reputação nas ocasiões em que lhe sobrevém alguma perda; mas naquelas em que ele se arruinaria completamente, o direito internacional [droit des gens] o dispensa de sua promessa."
} 
uma qualidade moral inerente à própria pessoa, mas o poder do soberano. $\mathrm{O}$ direito, nesse sentido, é sempre uma criação do soberano. - O direito é sempre direito positivo. Por essa razão, Descartes pode ser considerado, a meu ver, um precursor do positivismo legal, ainda que ele jamais tenha formulado claramente o projeto de fazer do direito positivo um âmbito de investigação sistemática, autônomo relativamente à ética.

É importante notarmos, porém, que, ao dissociar a fonte do direito de considerações de ordem moral ou religiosa, Descartes não estava endossando uma concepção absolutista de Estado. Por paradoxal que possa parecer, a separação dos âmbitos do direito e da moral pode ser ela própria justificada por razões morais. Uma das razões históricas para o surgimento do positivismo legal, como salienta Neil Maccormick, é que a partir do momento em que a existência do direito é explicada sem o recurso a teses metafísicas ou teológicas, os indivíduos, compelidos a viverem pacificamente por força da autoridade do soberano, deverão ser "tolerantes" uns relativamente aos outros, ainda que discordem amplamente das concepções morais e religiosas que endossam no âmbito de suas vidas privadas.

“... uma das raízes históricas do apelo do positivismo tem sido que, ao desvincular o conceito de direito de uma associação dogmática a qualquer filosofia moral ou teoria da justiça determinadas, cria-se um espaço intelectual e político para a tolerância e pluralismo democráticos." ${ }^{40}$

A despeito das diferenças que há entre Grotius e Descartes, parece-me que ambos filósofos tentaram dar conta da questão relativa à legitimidade da autoridade política dissociando o direito de certos princípios que, até então, eram tomados como constitutivos do direito. Grotius desvincula o direito de premissas teológicas. O "direito" (jus), no sentido estrito do termo, é para Grotius uma "qualidade moral" que justifica moralmente o indivíduo a fazer o que for necessário para garantir a satisfação de seus interesses mais básicos. Descarte, de certa maneira, dá um passo além e desvincula o "direito" (droit) não apenas de ideias teológicas, mas também de qualquer ideia moral.

\section{Conclusão}

Embora o jusnaturalismo e o positivismo legal sejam tradicionalmente vistos como teorias antagônicas, quando considerados a partir de uma perspectiva histórica, percebemos que, originalmente, os precursores dessas teorias estavam empenhados em dar conta de alguns problemas concretos, característicos da cultura intelectual e política do século XVII. Nesse sentido, não

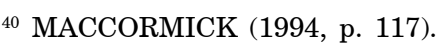


seria equivocado reconhecermos, como sugere, por exemplo, Jan Schröder, que há uma espécie de continuidade entre o jusnaturalismo e positivismo legal quando essas duas correntes são examinadas a partir de uma perspectiva histórica. Como ele afirma: "Deve-se reconhecer que a teoria jusnaturalista do Estado termina por valorizar o direito positivo e assim, paradoxalmente, constitui uma das raízes do positivismo legal contemporâneo. ${ }^{\prime \prime 1} \mathrm{O}$ que marca a continuidade na filosofia de Grotius e Descartes, como procurei mostrar neste artigo, é o interesse em lidar com o problema do ceticismo moderno, chamando atenção para certas características de que os indivíduos seriam sujeitos independentemente de sua inserção em uma comunidade política determinada.

\section{Bibliografia}

ACZEL, Amir. Descartes's Secret Notebook: A True Tale of Mathematics, Mysticism, and the Quest to Understand the Universe. Nova York: Broadway Books, 2005.

AQUINO, Tomás de: Suma Teológica (trad. Aldo Vannucchi et alii). São Paulo: Loyola, vol. 4, 2005.

ARAUJO, Marcelo de. Scepticism, Freedom, and Autonomy: The Moral Foundations of Descartes' Theory of Knowledge. Nova York / Berlim: De Gruyter, 2002.

ARAUJO, Marcelo de. "Hugo Grotius, contractualism, and the concept of private property: an institutionalist interpretation". In: History of Philosophy Quarterly, vol. 26, 2009, p. 353-371.

BENTHAM, Jeremy. “Anarchical Fallacies” [ca. 1791]. In: J. Waldron (org.), Nonsense upon Stilts: Bentham, Burke and Marx on the Rights of the Man. Londres: Metheuen, 1987, p. 46-76.

BURKHARDT, Helmut; GRÜNZWEIG Fritz, et alia (orgs.). "Gesetz". In: Das grosse Bibellexikon. Wuppertal / Giessen: Brockhaus / Brunnen, 1980, vol. 2, p. 694-706.

CONSTANT, Benjamin. "The liberty of the ancients compared to that of the moderns" [1819]. In: Benjamin Constant: Political Writings (trans. Biancamaria Fontana). Cambridge: Cambridge University Press, 1993, p. 307-328.

DARWALL, Stephen. "The foundations of morality: virtue, law, and obligation". In: Donald Rutherford (org.), The Cambridge Companion To Early Modern Philosophy. Cambridge: Cambridge University Press, 2006, p. 221-249

D'ENTRÈVE, A. P. Natural Law: An Historical Survey. Nova York: Harper Torchbooks, 1951.

DESCARTES, René. Oeuvres de Descartes, C. Adam e P. Tannery (orgs.) [1911]. Paris: Vrin, 1996.

${ }^{41}$ SCHRÖDER (2006, p. 20). 
DESCARTES, René. Discours de la Méthode: Texte et Commentaire (editado por Étienne Gilson). Paris: Vrin, 1962.

FINNIS, John. Natural Law and Natural Rights. Oxford: Clarendon Press, 1980.

GAUKROGER, Stephen. Descartes: An Intellectual Biography. Oxford: Oxford University Press, 1997.

GOUGH, J. W. The Social Contract: A Critical Study of its Development. Oxford: At the Clarendon Press, 1967.

GROTIUS, Hugo. O Direito da Paz e da Guerra (trad. Ciro Mioranza). Ijuí: Editora Unijuí, 2004.

GROTIUS, Hugo. De jure Belli ac Pacis Libri Tres, in quibus Jus Naturae \& Gentium, item Juris Publici præcipua explicatur. Nova York: William S. Hein, 1995. (Facsímile da edição de 1646).

GROTIUS, Hugo. Commentary on the Law of Prize and Booty (trans. Gwladys L. Williams). Indianapolis: Liberty Fund, 2006.

HAAKONSSEN, Knud. "Hugo Grotius and the history of political thought". In: Political Theory, vol. 13, 1985, p. 239-265.

HAAKONSSEN, Knud. "Divine / Natural law theories in ethics". In: D. Garber e M. Ayers (orgs), The Cambridge History of Seventeenth-Century Philosophy. Cambridge: University Press, vol. 2, 1998, p. 1317-1357.

HARRISSON, Ross. Bentham. Londres: Routledge, 1999.

HOBBES, Thomas. Leviathan [1651]. Cambridge, Cambridge University Press, 1996.

KELSEN, Hans. Was ist Gerechtigkeit? Stuttgart: Reclam, 2000.

LEVI, Anthony. Cardinal Richelieu: And the Making of France. Nova York: Carroll \& Graf Publishers, 2000.

MACCORMICK, Neil. "Natural law and the separation of law and morals". In: Natural Law Theory: Contemporary Essays, R. George (org.). Oxford: Clarendon Press, 1994, p 105-133.

MACINTYRE, Alasdair. After Virtue: A Study in Moral Theory. Indiana: University of Nortre Dame Press, 1981.

MACPHERSON, C. B. The Political Theory of Possessive Individualism: Hobbes to Locke. Oxford: Oxford University Press, 1964.

MAUTNER, Thomas. "Grotius and the skeptics". In: Journal of the History of Ideas, vol. 66, 2005, p. 577-601.

JACOBUS, Melancthon; NOURSE, Edward et alia (orgs.). "Law and legal practices". In: A New Standard Bible Dictionary. Nova York: Funk \& Wagnalls, 1962, p. 506-510.

MONTAIGNE: Les Essais. Paris: Les Livres de Poche, tomo 1, 1965.

MOOTE, A. Lloyd. Louis XIII: The Just. Berkeley: University of California Press, 1991.

NOVUM TESTAMENTUM TETRAGLOTTON. (edição tetralíngue: latim, grego, alemão, inglês), Zurique: Diognes, 1981.

Síntese, Belo Horizonte, v. 38, n. 120, 2011 
POPKIN, Richard. The History of Scepticism from Erasmus to Spinoza. Berkeley: University of California Press, 1979.

SCHMITT, C. Cicero Scepticus: A Study of the Influence of the Academica in the Renaissance. Hague: Nijhoff, 1972.

SCHNEEWIND, J. B. Moral Philosophy from Montaigne to Kant: An Anthology. Cambridge: Cambridge University Press, 1990.

SCHNEEWIND, J. B. "Natural law, skepticism, and methods of ethics". In: Journal of the History of Ideas, 1991, vol. 52, 289-308.

SCHNEEWIND, J. B. The Invention of Autonomy: A History of Modern Moral Philosophy. Cambridge: Cambridge University Press, 1998.

SCHNEIDERS, Werner. Naturrecht und Liebesethik: zur Geschichte der praktischen Philosophie im Hinblick auf Christian Thomasius. Nova York: Olms, 1971.

SCHÖDER, Jan: "Politische Aspekte des Naturrechts in der zweiten Hälfte des 17. Jahrhunderts: Die Begründung des staatlichen Rechtserzeugungsmonopols". In: Diethelm KLIPPEL (org.), Naturrecht und Staat: Politische Funktionen des europäischen Naturrechts. Munique: Oldenburg, 2006, p. 19-34.

SKINNER, Quentin. "Modernity and disenchantment". In: James TULLY (org.), Philosophy in an Age of Pluralism: The Philosophy of Charles Taylor in Question. In: Cambridge: Cambridge University Press, 1994, p. 37-48.

TUCK, Richard. “Grotius, Carneades, and Hobbes”. In: Grotiana, 1983, p. 43-62.

TUCK, Richard. "The 'modern' theory of natural law". In: Anthony PAGDEN (org.), The Languages of Political Theory in Early-Modern Europe. Cambridge: Cambridge University Press, 1987, p. 99-119.

TUCK, Richard. "Grotius and Selden". In: J. H. BURNS e Mark GOLDIE (orgs.), The Cambridge History of Political Thought, 1450-1700. Cambridge: Cambridge University Press, 1991, p. 499-529.

TUCK, Richard. The Rights of War and Peace: Political Thought and Political Order from Grotius to Kant. Oxford: Oxford University Press, 1999.

WESTERMAN, Pauline. The Disintegration of Natural Law Theory: Aquinas to Finnis. Leiden: Brill, 1998.

WILKERSON, K. E. "Carneades at Rome: a problem of sceptical rhetoric". In: Philosophy and Rhetoric, vol. 21, 1988, p. 131-144.

Endereço do Autor:

Rua Luiz Cantanhede 77, ap. 403

Laranjeiras, Rio de Janeiro - RJ

CEP 22245-040

e-mail: dodeskadan@yahoo.co.uk 